\title{
STUDYING REQUIREMENTS FOR SUBSTANTIONAL LIST OF PROFESSIONAL KNOWLEDGE FOR STUDENTS OF AGRICULTURAL ENGINEERING SPECIALITIES
}

\author{
Stanislav Nikolaenko ${ }^{1}$, Maria Bondar ${ }^{1}$, Oksana Bulgakova ${ }^{1}$, Valentina Vasileva ${ }^{2}$, Kaspars Vartukapteinis ${ }^{3}$ \\ ${ }^{1}$ National University of Life and Environmental Sciences of Ukraine, Ukraine; \\ ${ }^{2}$ University of Ruse Angel Kanchev, Bulgaria; \\ ${ }^{3}$ Latvia University of Life Sciences and Technologies, Latvia \\ semjons@apollo.lv
}

\begin{abstract}
Training in agricultural universities of mechanical, process and design engineers for the field of agroindustrial production in modern conditions requires new approaches that provide a higher level of knowledge in comparison with the already working specialists. The research solved the following main tasks: a) consideration, establishment and analysis of the concepts of professional competence of an engineer; b) by means of expert survey of employers determination of rank correlation of necessary competences to consider aspects of their formation at engineering faculties of agrarian universities; c) by results of the expert survey establish whether a graduate of an engineering faculty has significant competences and exactly which, and after what time they began to manifest. The analysis of the results of the employers' survey has shown that the main and significant part of agribusiness managers believe that for graduates of mechanical and technological faculties, the important competence of higher engineering education is a thorough knowledge of the structure of modern high-tech equipment and agricultural machinery. Another part of the interviewed employers believe that the main competence of an agricultural engineer should be: firstly - deep theoretical knowledge, which forms the engineering competence of a specialist; secondly - no less important, conscious understanding of the features of agro-business relations; thirdly - readiness for selfimprovement. Graduate of an agro-engineering faculty of a university should acquire such knowledge, which will allow him at the beginning of his production activity to adapt as soon as possible to the real conditions. Then in insignificant time terms he is involuntarily forced to lag behind the "practitioners" at the beginning, but during the following terms from 1 to 19 months he gains advantage (according to the expert group survey), thanks to the new, acquired knowledge obtained through new teaching methods and with the help of IT-technologies.
\end{abstract}

Keywords: knowledge, teaching methods, employers, survey, competence.

\section{Introduction}

Improving the quality of modern engineering education is aimed at training professionals possessing a set of competencies that fully meet the requirements of employers. Engineers in the fields of agricultural engineering, technical service and commodity agro-industrial production should possess not only professional knowledge, skills and abilities, but also be ready for their independent, creative application and improvement. This is one of the important scientific and practical tasks for the national education system and to no less extent - the production sphere. After all, employers, not infrequently, face the problem of mismatch between the competencies of graduates and the requirements of production. This is often due to inconsistency between educational and professional programs in which future young specialists are trained.

In this connection, there is a need for researches devoted to determining the degree of readiness of agrarian engineering graduates to productive activities. Here, an effective mechanism to improve the educational process is the close cooperation of universities with employers, and, first of all, to substantiate the content component of the set of necessary competences with subsequent formation and coordination with them of professional, educational standards of modern engineering training $[1 ; 2]$.

The study of studies and publications devoted to the problems of defining the competencies of graduates of higher professional education institutions and their compliance with the requirements of employers allowed to form the main conclusion about the incompleteness of the discussion regarding definitions, terminologies, meanings, structural elements and other categories of the scientific problem of filling the competencies of a graduate of higher education institutions with content. In this connection, the study [3], where the authors have done a huge scientific work, which is a systematic review where 84 scientific articles are considered, turned out to be indicative of interest. The review aimed to summarize the current level of research focused on education and curricula, touching on the concept of competencies and covering a period of 20 years - from 1997 to 2017. Based on this review, the authors suggested that there are two different labels for "competencies" in education [2]. Namely: from the theoretical point of view, competence is conceived as a cognitive structure that promotes a certain behavior; from the operational point of view, competencies, the authors suggest, cover a wide range of 
higher-order skills and behaviors, representing the ability to deal with complex, unpredictable situations; this operational definition includes knowledge, skills and strategic thinking, and assumes conscious and intentional decision-making [3]. Also, competence is defined as the integration of knowledge, skills and attitudes that allow a person to perform a certain task in vaguely defined and unique environments [4]. Collaborative research [5] by LiHua Cui (China), HyeJeong Kim (Seoul, Korea), and De Li (China) aimed to investigate which factors should be considered first to develop the core competencies needed in business. The study measured reliability and analyzed compliance based on the core competencies suggested by the DeSeCo project and questionnaire questions developed by the Korea Education Development Institute (KEDI). The main goals of this study were to facilitate students' adaptation to vocational training. A limited number of participants participated in this study, and according to the authors, this made it difficult to generalize the results of the study. In [6] the authors present an educational approach with key competencies, including seven general competencies. The scholars argue that the promotion of key competencies is a pivotal contribution to the discussion, as it does not support any particular normative position, and is relevant to all parties. The authors insist on a more comprehensive and effective concept of key competencies that goes beyond the narrow focus of skills training. The paper [6] presents the structure of key competencies:

- ability to demonstrate individual needs and cultural orientation;

- ability to plan, implement, and evaluate activities related to consumption;

- interact in heterogeneous groups;

- ability to critically take on the role of an active market participant;

- ability to report sustainable consumption;

- use the tools interactively;

- ability to use, edit, and share different forms of knowledge;

- ability to use information and communication technologies in an interactive mode;

- ability to think far-sightedly and consider interconnectedness.

Based on their own research the authors conclude that "...addressing competencies and the development of these competencies offers a structure, in which we can make informed decisions for successful learning. Problem-based learning in conditions of independent and collaborative work with meaningful tasks for students proved to be a strong factor contributing to such learning" [6]. In a study [7] separating the results of education (i.e. disciplinary knowledge) from the requested competencies, the author argues that firms primarily reward for competencies and to a much less extent reward for the disciplinary knowledge itself. Cultural background tends to become more important than formal education in shaping required competencies. The Bologna Process could disrupt this situation, provided it is integrated with a constructivist pedagogical approach, which tools are lacking today, but are vital in providing learning processes that enable students to acquire and develop the competencies needed in modern production technology.

Kihun Kim notes in [8] that not a single international comparative study clearly defines the concept of key competence. However, there are various international comparative studies specifically aimed at measuring the capabilities equivalent to key competencies.

In exploring the issues related to the concept of competencies in engineering education one cannot ignore the achievements of the International Engineering Alliance (IEA) [9]. The organization declares its ambition to improve engineering education and competence around the world. The IEA brings together three international agreements concerning the provision of an educational framework for professional engineers and process engineers. These are the Washington Accord (1989), the Sydney Accord (2001) and the Dublin Accord (2002). Formerly known as the Engineers Mobility Forum (EMF), the International Professional Engineers Accord (IPEA) is a multinational agreement between engineering organizations that provides a framework for establishing an international competency standard for professional engineers. The competency standard applied is the same as in the APEC Engineering Agreement. The main activities of the IEA [10]:

- consistent improvement of engineering education standards, thereby promoting the mobility of graduates;

- defining the content of engineering education standards and professional competence; 
- ensuring the objective accreditation of educational programs and evaluating the competence of graduates;

- participation in activities related to the engineering profession.

The graduate competencies, adopted by the signatories of the Washington Accord are the standard for the education of professional engineers from all engineering disciplines. The competency content categorizes what graduates should know, the skills they should demonstrate, and the skills they should possess. The graduate competency content has been refined over more than a decade and was adopted in 2013 as a benchmark against which to assess the equivalence of one's own standards to accreditation requirements. The detailed contents of the competency attributes are given in the brochure [10].

The Organization for Economic Cooperation and Development (OECD) adopted the program "Defining and Selecting Competencies: Theoretical and Conceptual Framework" (DeSeCo). The program was based on four main activities [11]:

- analysis of existing (at that time) studies of competencies was conducted with a focus on how the defining concepts were used. As a result, a significant inconsistency of views was found, indicating the need for a comprehensive grounding in the basics;

- assisted in the justification of the general concept of competence, aimed at the formation of a coherent understanding of the key provisions.

- based on research, based on choice, experts established an initial set of key competencies. This involved scientists, experts from different fields of knowledge, who worked together to come to a consensus and contribute to the definition of key competencies relevant to education.

- country consultations within the OECD to verify how the participating countries defined and selected the set of competencies.

The world practice of professional training of the engineering and technical specialists has already accumulated considerable experience. Agreements of organisations, responsible for the accreditation or recognition of engineering qualifications of the highest level, are united by one goal - to facilitate the mobility of professional engineers having appropriate qualifications. The activities of the parties that have signed the Agreement on the development of samples of the graduates' profiles are aimed at promoting the growing globalisation of mutual recognition of engineering qualifications [8].

In post-Soviet countries, including our country, in the National Doctrine of Education Development in Ukraine in the XXI century, it was determined that the main goal of the Ukrainian education system is to create conditions for the development and self-realization of each individual. Moreover, the scientific-pedagogical community asserts the opinion that the staff training for professional sphere should be based on the competence-based approach. The competence approach in education is based on the notion of competence and competence, which are rather productively studied in pedagogical science, but, nevertheless, do not have unambiguous content and definition, and are often used as synonyms.

The main purpose of the investigation is to study the possibilities to increase the degree of readiness of the students of agroengineering specialities for quick adaptation in the future professional activities and adjusting the content component of a set of professional competencies.

\section{Materials and methods}

This research is based on the analysis of scientific literature, clarification of the state of the problem development, highlighting the structural components of the set of competencies of engineering graduates in higher agricultural educational institutions; abstraction and forecasting - to determine the research conditions and formulate the hypothesis; modeling - to develop methods to substantiate the content of the set of competencies necessary for a graduate in future independent engineering activity; expert survey to identify weaknesses. There is also every reason to state that for the first time, using the means of pedagogical technologies focused on the notions of competencies in education, the methodology of substantiation of the content component of the set of professional competencies of current employees of engineering and technical services, setting the goal of diagnostics, self-diagnostics and selfimprovement, the most important quality of university engineering training - readiness of engineering graduates for future activities in production. 
In order to assess the degree of fulfillment of requirements to knowledge, skills and practical experience of graduates of specialties - industrial engineering and agricultural engineering, a complex application of both direct and indirect methods of obtaining statistical information was provided, which is explained by the diversity of the problem under study and allows to determine the individual attitude of respondents to certain key competences and obtain representative information, which will allow to make rational decisions The research itself was conducted in two stages. The first stage was an anonymous questionnaire survey of graduates and employers, and the second stage was an expert survey.

At the first stage, a questionnaire was used as an instrument, and the respondents were acting specialists: working in different positions engineers of machine-building enterprises, dealerships, technical service organizations, civil servants of various departments of agriculture, as well as specialists of engineering and technical services of agroindustrial production, who were asked to answer the questionnaire questions with detailed answers to open questions and questions with certain options of answers to them. The content of the questions concerned the sphere of professional education and, in particular, motivation for professional self-study and self-improvement in the production sphere. One of the open-ended questions concerned the respondent's opinion on the concepts of "qualified" and "competent" specialist. Namely, whom did the respondent prefer to have in his/her subordinate. It was explained as follows: skilled - (master) skilled, skillful, experienced, practitioner, trained; competent (expert) knowledgeable, knowledgeable; (official) full-fledged, competent. A total of 162 respondents participated in the survey. Based on the processing of the results of the survey, we can make the following conclusions: $67.9 \%$ of respondents answered that they would prefer a competent specialist, $21.6 \%$ believe that it is better to have a qualified specialist, and $11.5 \%$ of respondents believe that these are identical concepts. At the second stage of the study, the expert survey, the heads of various organizations, which had graduates of December 2016 in their subordination, specialties: industrial engineering; agroengineering, acted as experts. A total of 78 managers were interviewed monthly from February 2017 to September 2018. They were asked to assess the competence of graduates on a 12-point scale for the set of eight competencies offered, containing an appropriate set of knowledge abilities and skills. At the same time, the respondents had to simultaneously assess by the same parameters their fulltime employee, a practitioner, who had worked at the company for at least three years and performed similar duties.

The data collected on a monthly basis were analyzed. The results of the expert survey were processed using mathematical and statistical methods: the analysis of correlation matrices (SPSS package) was used to identify statistically significant rank correlations; Spearman rank correlation method was used to identify statistically significant rank correlations; calculation of indicators and charting (processing in Statistica 6 and MS Excel 2010). The values of dispersion and mean square deviation confirm that the results are statistically significant. In order to assess the degree of fulfillment of requirements to knowledge, skills and practical experience of graduates of specialties - industrial engineering and agricultural engineering, a complex application of both direct and indirect methods of obtaining statistical information was provided, which is explained by the diversity of the problem under study and allows to determine the individual attitude of respondents to certain key competences and obtain representative information, which will allow to make rational decisions. The research itself was conducted in two stages. The first stage was an anonymous questionnaire survey of graduates and employers, and the second stage was an expert survey.

At the first stage, a questionnaire was used as an instrument, and the respondents were acting specialists: working in different positions engineers of machine-building enterprises, dealerships, technical service organizations, civil servants of various departments of agriculture, as well as specialists of engineering and technical services of agroindustrial production, who were asked to answer the questionnaire questions with detailed answers to open questions and questions with certain options of answers to them. The content of the questions concerned the sphere of professional education and, in particular, motivation for professional self-study and self-improvement in the production sphere. One of the open-ended questions concerned the respondent's opinion on the concepts of "qualified" and "competent" specialist. Namely, whom did the respondent prefer to have in his/her subordinate. It was explained as follows: "skilled - (master) skilled, skilful, experienced, practitioner, trained; competent (expert) knowledgeable, knowledgeable; (official) full-fledged, competent. A total of 162 respondents participated in the survey. Based on the processing of the results of the survey, we can make the 
following conclusions: $67.9 \%$ of respondents answered that they would prefer a competent specialist, $21.6 \%$ believe that it is better to have a qualified specialist, and $11.5 \%$ of respondents believe that these are identical concepts. At the second stage of the study, the expert survey, the heads of various organizations, which had graduates of December 2016 in their subordination, specialties: industrial engineering; agroengineering, acted as experts. A total of 78 managers were interviewed monthly from February 2017 to September 2018. They were asked to assess the competence of graduates on a 12-point scale for the set of eight competencies offered, containing an appropriate set of knowledge abilities and skills. At the same time, the respondents had to simultaneously assess by the same parameters their fulltime employee, a practitioner who had worked at the company for at least three years and performed similar duties.

The data collected on a monthly basis were analyzed. The results of the expert survey were processed using mathematical and statistical methods: the analysis of correlation matrices (SPSS package) was used to identify statistically significant rank correlations; the Spearman rank correlation method was used to identify statistically significant rank correlations; the calculation of indicators and charting (processing in Statistica 6 and MS Excel 2010). The values of variance $\left(S^{2} x\right)$ and standard deviation $(S x)$ confirm that the results are statistically significant.

\section{Results and discussion}

Universities, which represent the sphere of higher professional education, and enterprises, which represent the sphere of production, cannot exist in isolation from each other. On this basis, an effective mechanism for improving the educational process is close cooperation between universities and employers, in our case - mechanical engineering and agricultural production. A prerequisite for highquality training of future industrialists, and a very important factor of synergetic effect, is the presence of constant feedback - effective communication between the university and the industry. Very often such communication is in the format of attracting employers to actively participate in the formation of curricula, specialties and specializations. At the same time, universities and industry face the problem of different interpretations of exactly what knowledge, skills and abilities are needed to minimize the time of a graduate's adaptation to production. The development and improvement of pedagogical science and educational management has led to the emergence of new, more effective tools and technologies, allowing to significantly increase the synergistic effect of the combined efforts of the university and the manufacturer aimed at accelerated growth of graduates' professional skills and ensuring their mobility in the process of mastering innovative technologies. One of these tools allowing to strengthen the effective feedback of the enterprise and the university is the competence-based approach - a pedagogical technology focused on the concept of competences in education (competencebased-education-CBE). Professional competence is inseparably connected with self-development and self-education of a personality, it is determined by the level of professional education, as well as by the experience and individual abilities of a person, his desire for continuous self-improvement and selfeducation, creative attitude towards business [13-15].

In preparation for the study, the results of the analysis of the scientific literature and to clarify the state of development of the problem we came to a decision to take as a basis the concept of "competence", "competence" and "competence" in the version of the authors [4], namely:

- "...competence is ... a predetermined requirement for knowledge and experience in a particular area;

- competencies - generalized ways of action that ensure productive performance of professional activities; they include: knowledge and understanding (theoretical knowledge, the ability to know and understand) knowledge how to act (practical operational application of knowledge in specific situations); knowledge how to be (values that are integral to the perception of life with others in a social context);

- competence is the possession of competence, manifested in effective activity and includes personal attitude to the subject and the product of activity; ... is a system concept, has its own structure, levels, functions, peculiar characteristics, properties;

- one can become competent by mastering certain competences and implementing them in the experience of concrete activity". 
Using the notion of competencies as a predetermined requirement for knowledge and activity experience in the field of mechanical and agro-engineering engineering, a list of requirements, i.e., competencies was prepared, the content of which was discussed and agreed at the meeting of the National University of Life and Environmental Sciences of Ukraine and Ukraine Council of Employers. Eight key competences were selected from the agreed list. The graphs (Fig. 1) show the dynamics of competence assessment throughout the study.

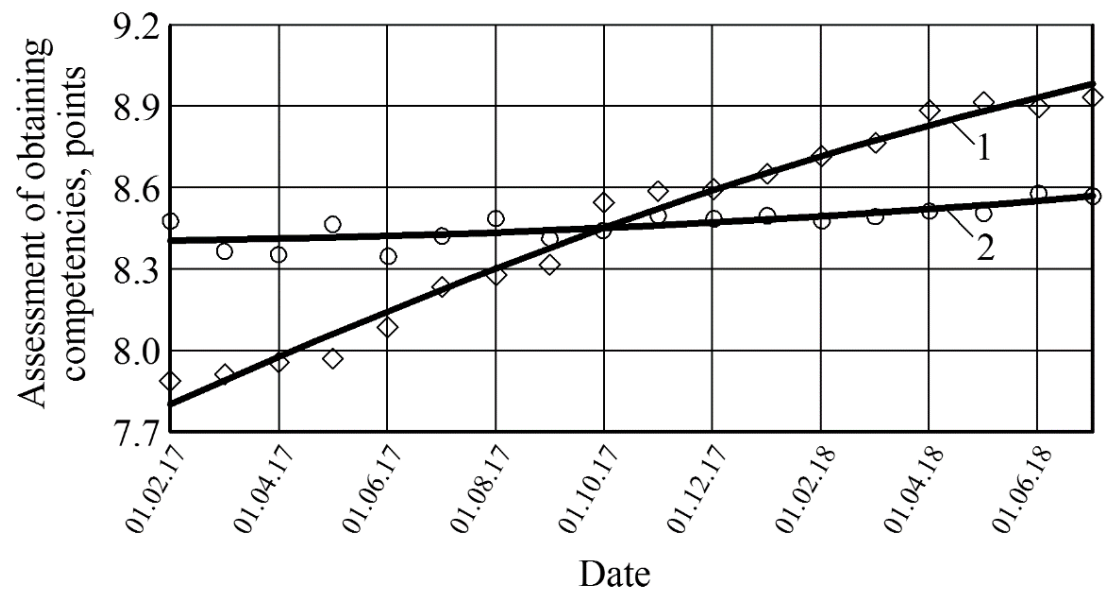

Fig. 1. Dynamics of assessing competencies of graduates and staff specialists:

1 - Graduate December 2016; 2 - Full-time specialist, practitioner with at least three years of experience

As it can be seen from the graphs presented in Fig. 1, first of all, the necessary indicative dynamics of growth of key competences of engineering graduates of December 2016 is traced in comparison with full-time specialists, practitioners with at least three years of experience. That is, a trainee with production experience remains quite a qualified specialist until he/she faces new high-tech means of production and his/her qualification goes together with the old equipment. In contrast, a graduate with key competences and a sufficiently strong motivation for self-study and self-improvement, i.e. for professional self-development, adapts quickly enough in production.

\section{Conclusions}

For the first time, by the means of pedagogical methods, focused on the concept of competencies in education, a methodology has been developed to substantiate the content component of the set of professional competencies of the existing employees of engineering and technical services, which are directed at diagnostics, self-diagnostics and self-improvement, the most important quality of university engineering training - readiness of the graduates of engineering specialties for the future activities in the production area.

Competence is an important personality quality structure for engineering graduates. According to the results of the study it was found that graduates with high level of competence in production situations choose strategies aimed at solving problems, they are motivated by the desire to achieve success, ready for self-improvement, not to move away from their social environment, and also strive to maintain communication with colleagues and take responsibility for their own decisions. Graduates with low competence in production situations try to avoid solving production problems on their own, and, more often than not, devalue the significance of their consequences.

Prospects for further research are seen in a more in-depth study of competence as an indicator of personality quality of engineering graduates, as well as in the study of the dynamics of competence development depending on the motivation for professional self-improvement.

\section{References}

[1] Nikolaenko S., Bondar M., Bulgakova O., Dukulis I. Investigation of pedagogical conditions for development of professional self-perfection skills of future agricultural engineers. Engineering for Rural Development, 19, 2020, pp. 1364-1372. 
[2] Nikolaenko S., Bulgakova O., Dukulis I., Pilvere I. Methodological aspects of training future agroengineers. Engineering for Rural Development, 18, 2019, pp. 1933-1940

[3] Tahirsylaj A., Sundberg D. The unfinished business of defining competences for 21st century curricula - a systematic research review. Curriculum Perspectives, 40 (2), 2020, pp.131-145.

[4] Egodawatte G. An analysis of the competency-based secondary mathematics curriculum in Sri Lanka. Educational Research for Policy and Practice, 13.1, 2014, pp. 45-63.

[5] Cui L. The Relationship between Core Competence and Self-Efficacy for Qualitative Improvement of Industrial Technology Training. International Journal of u-and e-Service, Science and Technology, 7.1, 2014, pp. 1-8.

[6] Fischer D., Barth M. Key Competencies for and beyond Sustainable Consumption an Educational Contribution to the Debate. GAIA-Ecological Perspectives for Science and Society, 23.3, 2014, pp. 193-200.

[7] Leoni R. "Graduate employability and the development of competencies. The incomplete reform of the "Bologna Process", International Journal of Manpower, Vol. 35 No. 4, 2014, pp. 448-469

[8] Park H., Kim K. Kim K. Youth Key Competencies in Korea. Korean Education in Changing Economic and Demographic Contexts. Education in the Asia-Pacific Region: Issues, Concerns and Prospects, vol. 23, 2014. Springer, Singapore

[9] International engineering alliance: educational accords [online] [21.03.2021] Available at: https://www.ieagreements.org/assets/Uploads/Documents/Policy/Accord-Rules-and-ProceduresJuly-2018-version-2019.1.pdf

[10] 25 years. Washington Accord. [online] [21.03.2021] Available at: https://www.ieagreements.org/assets/Uploads/Documents/History/25YearsWashingtonAccordA5booklet-FINAL.pdf

[11] The definition and selection of key competencies: executive summary [online] [21.03.2021] Available at: http://www.oecd.org/pisa/35070367.pdf

[12] Magnell M. Academic staff on connections to professional practice and research in engineering education: a discourse analysis. European Journal of Engineering Education. Vol. 45, Issue 5, 2020 , pp. 780-793

[13] Shageeva F.T., Erova D.R., Kraysman N.V. Poster: Social-Psychological Readiness of Engineering University Students for Academic Mobility to European Countries Advances in Intelligent Systems and Computing, 1135 AISC, 2020, pp. 719-724. , doi: 10.1007/978-3-030-40271-6_71

[14] Kraysman N.V., Shageeva F.T., Pichugin A.B. Modern Pedagogical Techniques in Teaching French to Prepare Engineering University Students for Academic Mobility. Advances in Intelligent Systems and Computing. Vol. 1329, 2021, pp. 107-117

[15] Alpay E., Jones M.E. Engineering education in research-intensive universities. European Journal of Engineering Education, 37 (6), 2012, pp. 609-626.

[16] Jamison, A., Kolmos, A., Holgaard, J.E. Hybrid Learning: An integrative approach to engineering education Journal of Engineering Education, 103 (2), 2014, pp. 253-273. 